\title{
Heat Transfer and Performance Characteristics of Axial Cooling Fans with Downstream Guide Vanes
}

\author{
Alexandros Terzis, Ioannis Stylianou*, Anestis I. Kalfas* and Peter Ott \\ Group of Thermal Turbomachinery (GTT) \\ School of Engineering, EPFL-SCI-STI-PO, CH-1015, Lausanne, Switzerland \\ *Laboratory of Fluid Mechanics and Turbomachinery \\ Dept. of Mechanical Engineering, School of Engineering \\ Aristotle University of Thessaloniki (AUTH), GR-54124, Thessaloniki, Greece \\ (C) Science Press and Institute of Engineering Thermophysics, CAS and Springer-Verlag Berlin Heidelberg 2012
}

\begin{abstract}
This study examines experimentally the effect of stators on the performance and heat transfer characteristics of small axial cooling fans. A single fan impeller, followed by nine stator blades in the case of a complete stage, was used for all the experimental configurations. Performance measurements were carried out in a constant speed stage performance test rig while the transient liquid crystal technique was used for the heat transfer measurements. Full surface heat transfer coefficient distributions were obtained by recording the temperature history of liquid crystals on a target plate. The experimental data indicated that the results are highly affected by the flow conditions at the fan outlet. Stators can be beneficial in terms of pressure drop and efficiency, and thus more economical operation, as well as, in the local heat transfer distribution at the wake of the stator blades if the fan is installed very close to the cooling object. However, as the separation distance increases, enhanced heat transfer rate in the order of $25 \%$ is observed in the case of the fan impeller.
\end{abstract}

Keywords: axial fans, stators, performance, thermochromic liquid crystals, transient heat transfer

\section{Introduction}

Small fans, which are primarily axial machines, induce the air movement of a relatively large mass flow with comparatively low velocities. These machines find great applicability over a wide range of engineering applications for reasons of thermal management, as for example in cooling of electronics; one of the main concerns for the achievement of higher packaging densities which are required by the general trend of microminiaturization. However, the continuously raised heat fluxes create even more adverse operational conditions increasing temperatures. Additionally, the modern complex shapes of electronic boxes require even more pressure development through their cooling system in order to overcome the increased flow resistance. As a result, the achievement of optimum performance and thermal design is a big challenge for cooling engineers since the combination of complex spaces and high temperatures is an additional concern in order to ensure a reliable electronic system.

Several works have been published on cooling of electronic equipment [1-5]. A large number of high performance cooling techniques using both experimental and numerical data as well as liquid and air coolants have been presented [6-7]. However, direct air cooling through 


\begin{tabular}{clcl}
\hline Nomenclature & & \multicolumn{2}{c}{} \\
$\mathrm{a}$ & Thermal diffusivity $\left(\mathrm{m}^{2} / \mathrm{s}\right)$ & Greek & Separation distance \\
$\mathrm{C}_{\mathrm{P}}$ & Specific heat $(\mathrm{J} / \mathrm{KgK})$ & $\alpha$ & \\
$\mathrm{D}$ & Fan external diameter/Duct diameter $(\mathrm{m})$ & $\Delta \mathrm{P}$ & Flow angle $(\mathrm{deg})$ \\
$\mathrm{d}$ & Jet diameter $(\mathrm{m})$ & $\varepsilon$ & Pressure rise $\left(\mathrm{in}-\mathrm{H}_{2} \mathrm{O}\right)$ \\
$\mathrm{h}$ & Heat transfer coefficient $\left(\mathrm{W} / \mathrm{m}^{2} \mathrm{~K}\right)$ & $\eta$ & Flow deflection $(\mathrm{deg})$ \\
$\mathrm{k}$ & Thermal conductivity $(\mathrm{W} / \mathrm{mK})$ & $\omega$ & Overall efficiency $(-)$ \\
$N$ & Rotational speed $(\mathrm{r} / \mathrm{min})$ & subscripts & Angular velocity $(\mathrm{rad} / \mathrm{s})$ \\
$\mathrm{Q}$ & Volumetric flow $\left(\mathrm{m}^{3} / \mathrm{s}\right)$ & $\mathrm{a}$ & \\
$\mathrm{R}$ & Radius $(\mathrm{m})$ & $\mathrm{avg}$ & Axial \\
$\mathrm{T}$ & Temperature $(\mathrm{K})$ & $\mathrm{e}$ & Average \\
$\mathrm{t}$ & Time $(\mathrm{sec})$ & $\mathrm{i}$ & Electrical \\
$\mathrm{V}$ & Velocity $(\mathrm{m} / \mathrm{s})$ & $\mathrm{w}$ & Initial \\
$\mathrm{U}$ & Blade velocity $(=\omega \mathrm{R})$ & $\mathrm{h}$ & Wall \\
$\mathrm{x}, \mathrm{y}, \mathrm{z}$ & Coordinate system & $\mathrm{t}$ & hub \\
$\mathrm{Nu}$ & Nusselt number & $\mathrm{SFP}$ & tip \\
$\mathrm{Re}$ & Reynolds number & $\mathrm{TLC}$ & Specific Fan Power \\
$\mathrm{Pr}$ & Prandtl number & & Thermochromic Liquid Crystals \\
\hline
\end{tabular}

small fans or impingement jets, still remains an attractive cooling mechanism due to the inexpensiveness and the mechanical simplicity of the design. Additionally, forced air systems can provide heat transfer rates that are 10 times greater than those available with natural convection or radiation.

Small axial fans can be assumed as impingement jets with a relatively big stagnation point region. Impingement cooling, through single or multiple jets (fans) [8-11], finds great applicability in cooling of electronics due to the very high heat and mass transfer rate while the continuously injected coolant flow ensures very high heat fluxes in the stagnation region of the jet. However, the continuous demand for higher temperatures within the electronic boxes requires new cooling concepts and more advanced cooling techniques to be considered. The overall operational performance of small axial cooling fans in terms of pressure drop and heat transfer removal capabilities can be affected by many parameters. For example, blade metal angles [12] and tip leakages [13] can be a critical factor in determining how well a cooling fan will perform since the position of the fan blades within the axial flow fan housings affects the flow conditions. A new concept for further improvement of the performance and efficiency curves includes contra rotating fan impellers [14] however the increase in noise has to be considered [15]. Many other factors such as blade number, external diameter, hub/tip ratio etc. can affect the overall performance and the cooling efficiency of small axial fans. However, very little information of the effect of stators has been reported in the open literature.

This investigation examines experimentally the effect of stators on the performance and the heat transfer capabilities of small axial cooling fans. A single fan impeller, followed by nine stator blades in the case of a complete stage, was used for all the examined configurations. The constant speed stage performance method and the transient liquid crystal technique were used for the performance and the heat transfer experiments, respectively. The results are analyzed by various post-processing procedures aiming to clarify and quantify the effect of stators on the operability of the cooling fans at low separation distances $(Z / D=0.2,0.5$ and 1$)$ and normal rotational speeds (3000-6000r/min).

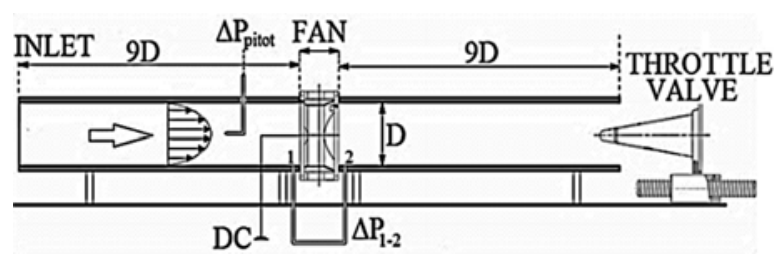

Fig. 1 Constant speed stage performance test rig

\section{Experimental Arrangement}

\section{Performance Measurements}

Fan impeller and fan stage performance experiments were carried out in the constant speed stage performance test rig of Aristotle University of Thessaloniki (AUTH), shown in Fig.1. The setup consists of long upstream and downstream ducts of constant area, the test section where the fans were mounted and a throttle valve at the exit plane. Air movement inside the pipe was induced by the 
fan impeller mounted in the middle of the test section and powered by an adjustable DC-Power Supply. The blade row of the fan impeller consists of seven rotor blades. The performance measurements of the fan impeller and fan stage performed with the same motor and rotor blades, followed by nine stator blades of the same hub to tip ratio $\left(R_{h u b} / R_{t i p}=0.4\right)$ in the case of a complete fan stage.

At a given rotational speed fan speed lines can be measured by varying the mass flow rate using a conical throttle valve at the exit plane of the test rig. The reduction of the exit plane area reduces the mass-flow rate increasing the pressure difference at a given rotational speed, until the surge point is reached. At this position the diffusing blade passage is no longer able to handle the positive pressure gradient and hence flow separation occurs. The pressure rise of the fan at each throttle point is measured directly upstream (1) and downstream (2) of the fan configuration, at four equally spaced radial pressure tapping holes.

Fan rotational speed was measured using an infrared laser tachometer (DT2234A) between 3000r/min and $6000 \mathrm{r} / \mathrm{min}( \pm 2 \mathrm{r} / \mathrm{min})$. A programmable stepper motor controller $( \pm 0.01 \mathrm{~mm})$ was used for the movement of the throttle while mass-flow was evaluated with a Pitot static tube placed in the centerline of the duct. The average axial velocity $(\sim 0.75 \mathrm{~V} \infty)$ was estimated with a probe traversing. Pressure signals were acquired using a calibrated high performance multi-channel pressure acquisition module (NetScanner 9016, $\pm 0.05 \%$ after re-zeroing) via LabVIEW. Totally, twelve sets of measurement data were collected for each speed line in order to derive the performance maps of the fan impeller (rotor) and fan stage (rotor and stator).

\section{Heat Transfer Measurements}

The heat transfer experiments were carried out in the low speed wind tunnel of GTT at EPFL. The test facility, shown in Fig.2, consists of an axial blower used as an air source, long upstream rectangle ducts, a heater mesh used for the temperature step in the flow, the fan impeller/stage placed at the exit of the tunnel and the target plate placed at three different separation distances of $Z / D=0.2,0.5$ and 1.0 .

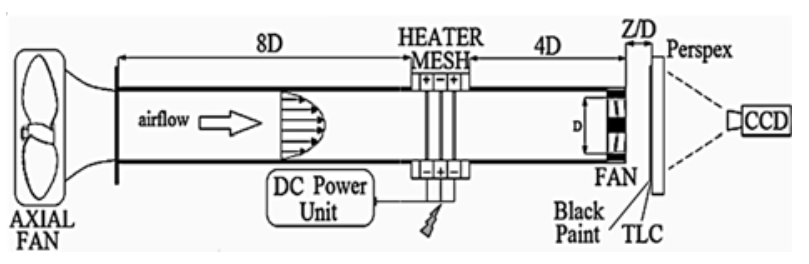

Fig.2 General layout of the low speed wind tunnel
The heat transfer experiments were carried out using the transient liquid crystal technique [16-18]. This technique uses the full surface temperature history derived from the colour of the liquid crystals in order to obtain full surface heat transfer coefficient distributions on the target plate. The main advantages are the high resolution obtained and the minimum intrusiveness of the flow. TLC are sprayed on the surface of the target plate using an air brush while black paint is applied above liquid crystals in order to create a black background providing brilliant colors. A narrow bandwidth type $\left(31.5^{\circ} \mathrm{C}-\right.$ $32.8^{\circ} \mathrm{C}$ ) of TLCs was used for all experiments while the green color was used for the post-processing. Liquid crystals were calibrated with a surface thermocouple glued in the middle of the target plate.

In a typical transient heat transfer experiment, the flow temperature is subjected to a sudden temperature step and the optical response of the liquid crystal surface coating is monitored using a digital video camera at the back of the target plate. If the thermal conductivity of the model is sufficiently low, the wall temperature response is limited to a thin layer near the wall surface while the lateral conduction is assumed relatively small and hence negligible. Therefore, the heat conduction into the model can be assumed to be one-dimensional when a semi-infinite medium approach is used. Numerical and analytical techniques can be used to solve the 1D transient conduction equations. The relation between the wall surface temperature, $\mathrm{T}_{\mathrm{w}}$, and the heat transfer coefficient, $h$ for the semi-infinite case is then described by:

$$
\frac{T_{w}-T_{i}}{T_{g}-T_{i}}=1-e^{\beta^{2}} \operatorname{erfc}(\beta) ; \quad \beta=h \sqrt{\frac{t}{\rho_{w} C_{w} k_{w}}}
$$

where, $\rho_{w}, C_{p w}$ and $k_{w}$ are the Perspex density, specific heat and thermal conductivity, $T_{i}$ and $T_{g}$ are the initial wall and gas temperatures and $t$ is the time from the initiation of the heating step. Gas temperature corresponds to the jet total temperature and is measured in the plenum. The temperature step in the flow achieved with a heater mesh [19], which has the capability of providing an almost instantaneous temperature step in the mainstream flow through the Joule Heating law. Three layers of metallic heater meshes, with open area of $25 \%$, were used for the initiation of the heating step. Power to the mesh is supplied through a 5kW DC-Power supply. The response time of the device needed to reach steady state condition has been measured to less than $60 \mathrm{msec}$ and hence assumed suitable for the creation of the temperature step in the flow. The temperature of the flow upstream of the fan was acquired via LabVIEW at a sampling rate of $25 \mathrm{~Hz}$.

A single jet configuration placed at the same position with the fans providing similar illumination and viewing angle settings was used for the validation of the measurement technique. The results of the standard single 
impingement case of $Z / d=2$ and $R e_{d}=23000$ were compared with literature data indicating good agreement over a certain radial distance, as shown in Fig.3.

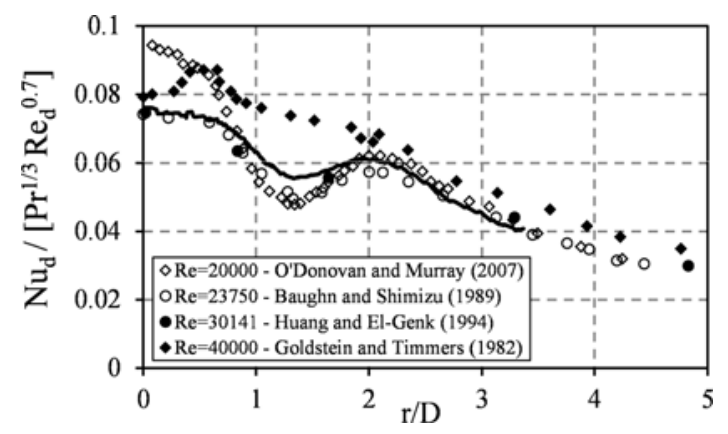

Fig. 3 Validation of the measurement technique

\section{Results and Discussion}

\section{Performance data}

Fan selection for a particular application is usually concerned with its characteristic curve which defines a relation between pressure and mass-flow. For axial fans and incompressible flows, due to the low developed pressure rise, the characteristic curve for standard atmospheric conditions can be expressed as a relation between the achievable static pressure difference and the mass flow rare at a given rotational speed. The main advantages of axial flow fans are their high efficiency, compactness and simplicity of installation. However, in all applications, fan selection involves choosing the most inexpensive combination of size, arrangement and type while providing stable operation.

Fig. 4 indicates the overall performance of the fan impeller and the fan stage configuration. Fig.4 (a) indicates the performance map of the two studied cases where on both situations the inclination of the curves in the unstalled part is constant as the rotational speed increases indicating the incompressible character of the flow. However, the slope of the speed lines is greater when guide vanes are installed after the fan rotor. This is due to the direct straightening of the flow and the pressure recovery achieved within the stators' passages. As a result, higher static pressure rise can be obtained for a given mass flow rate at given rotational speed. Increased values of static pressure are desirable when the geometry of the cooling object is relatively complex which result in a higher pressure drop through the cooling system. Although complex shapes, containing obstacles and roughened surfaces create turbulent flow conditions, and thus more heat to be removed is permitted, additional power is required in order to overcome the added flow resistance. However, the increase in static pressure is relatively low resulting in a reaction stage efficiency (static pressure rise achieved by the rotor divided by the static pressure rise achieved by the stator) of approximately $90 \%$. Additionally, the experimental data indicate that the installation of stators after the rotor maintains the operational mass flow range at a given speed line unaffected.

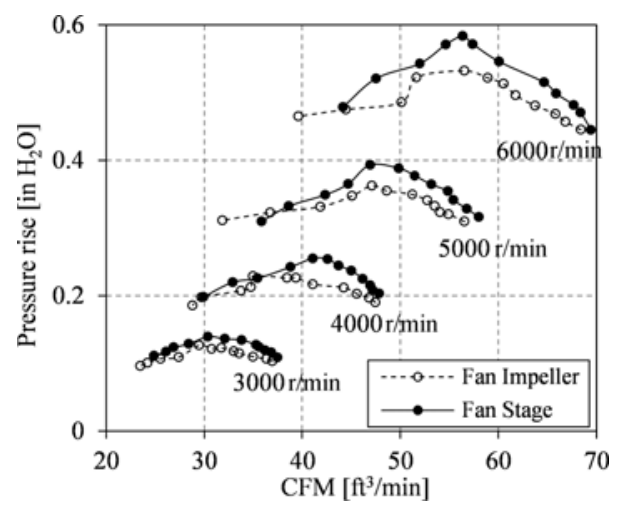

(a) Performance maps

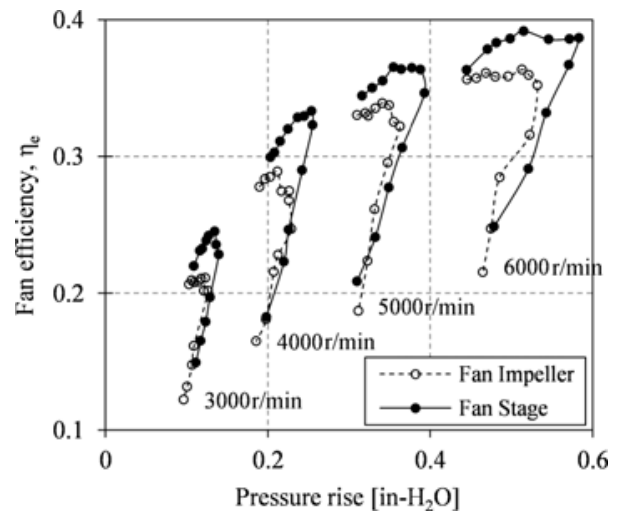

(b) Efficiency curves

Fig.4 (a) Performance maps and (b) efficiency curves for the fan impeller and the fan stage configuration

Fig. 4 (b) indicates the overall efficiencies for the two studied cases. Fan efficiency is defined as the ratio of the power transferred to the airflow to the power used by the fan, and can be expressed as:

$$
\eta_{e}=\frac{P_{\text {out }}}{P_{\text {in }}}=\frac{\Delta P_{\text {st }} Q}{V I}
$$

where $\Delta P$ is the static pressure rise, $Q$ is the volumetric flow and $P$ is the input and output power. In general, fan efficiency increases with rotational speed since the increase in static pressure and volume flow is higher than the increase in electrical consumption. Furthermore the best operation point in terms of maximum efficiency is different than the point of maximum power output since the peak in the efficiency curve is observed, as expected, before the surge point is reached. The efficiencies of the fan stage are higher compared with the fan impeller in the unstalled part of the characteristic curve due to the higher static pressure rise achieved through the fan stage at a given mass flow rate and hence electrical input (rota- 
tional speed). However, further decrease of mass flow (increase of pressure rise) results in stall of the rotor blade passage and a sharp reduction of the achievable pressure rise which degrades sharply fan efficiency. The differences in the efficiency curves are negligible in the stalled region between the fan impeller and the fan stage. The general trends and the slope of the curves are the same over the entire range of rotational speeds involved in this study indicating that no compressibility effects appeared.

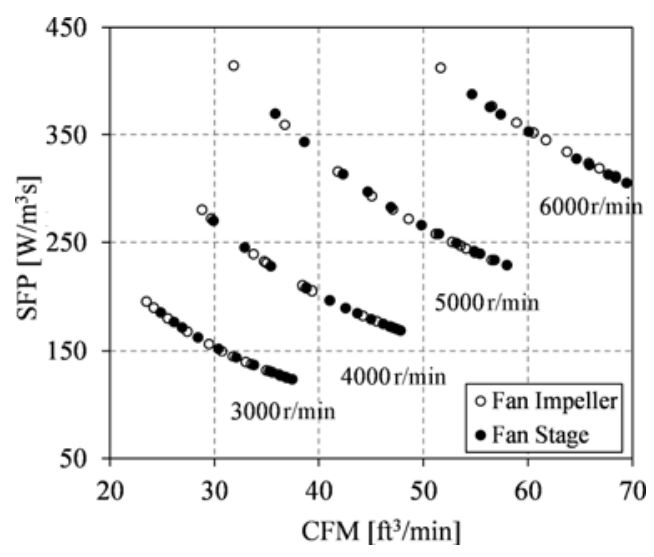

Fig. 5 Specific fan power for the fan impeller and the fan stage configuration

An alternative way of describing the energy efficiency is the Specific Fan Power (SFP) measured in $\mathrm{Ws} / \mathrm{m}^{3}$. SFP can be expressed in units of pressure, since pressure is a measure of energy per $\mathrm{m}^{3}$ air. The relation between SFP, fan pressure rise, and fan efficiency is simply:

$$
\mathrm{SFP}=\frac{\Delta P_{s t}}{\eta_{e}}
$$

where $\eta_{e}$ is the overall efficiency of the fan and $\Delta P$ is the total static pressure difference through the fan. Fig. 5 illustrates SFP for the fan impeller and fan stage as a function of mass flow rate at various speed lines. Contrary to overall efficiency curves (Fig.4a) there is no 'peak' or a 'best' operating point. At a given speed line, SFP is continuously reduced with increasing mass flow. Additionally, as expected, there is no difference between the SFP values of the fan impeller and the fan stage. This is because SFP is a measure of the electric power that is needed to drive a fan relative to the amount of air that is circulated through the fan. Given that rotational speed depends only on the electrical input and stators do not affect the operation range of the fan (Fig.5), installation of guide vanes after the rotor maintain the specific power of the fan system constant.

Fig. 6 indicates the deflection angle $(\varepsilon)$ and the exit flow angle $\left(\alpha_{2}\right)$ of the rotor blade for the two studied cases. The velocity triangles on the rotor blade of the fan stage have been calculated at the mid-span of the blade (50\% span) assuming a reaction stage efficiency of $90 \%$ as well as negligible radial equilibrium effect which means constant static pressure distribution along the blade span. A schematic of velocity triangles at the inlet and outlet of the rotor blade is presented in upper part of the figure. As the throttle valve (see Fig.1) reduces the exit flow area of the test rig and hence pressure rise is gradually increased, the exit flow angle $\left(\alpha_{2}\right)$ remains constant for the two studied cases, at approximately $55 \mathrm{deg}$ and is independent of the rotational speed. The reduced mass flow ( $V_{\alpha}$ in the upper figure) increases also the inlet flow angle $\left(\alpha_{1}\right)$ which in combination with the constant $\alpha_{2}$, result in a sharp increase of the deflection of the flow $\left(\varepsilon=\alpha_{2}-\alpha_{1}\right)$ in the unstalled part of the characteristic curve. The deflection angle reaches a maximum when the surge point is reached and therefore flow separation occurs. The separated flow blockages the blade exit area and destructs the diffusive character of the blade passage. Subsequently, further decrease of mass-flow steeply increases the exit flow angle $\left(\alpha_{2}\right)$ and therefore abrupt reduction of the deflection angle $(\varepsilon)$ is observed. Additionally, the deflection angle is slightly increased with the rotational speed while the smaller inclination of the curve at higher speed lines is a direct consequence of the broader operational range.
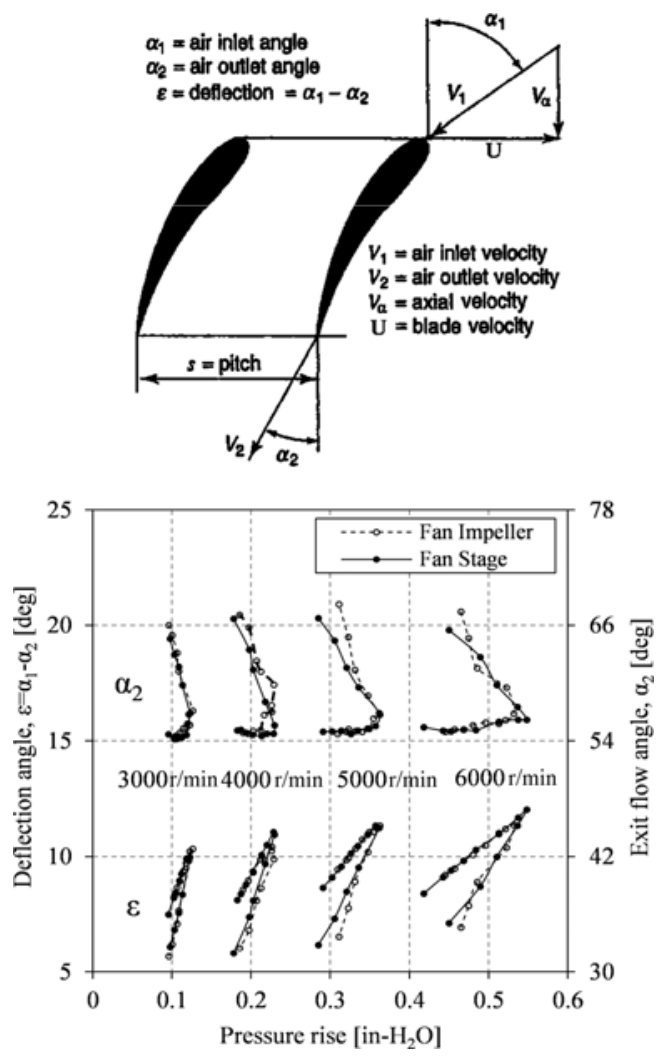

Fig. 6 Velocity triangles notation and flow angles for the rotor blade of the two studied cases 
Fig.6 indicates also that the flow angles, and hence the velocity triangles, are similar for the rotor of the fan impeller and the fan stage. This indicates that the behavior of the flow on the rotor blade is independent of any downstream guide vane installation. The contribution of stator is then limited on the transformation of the swirl velocity induced by the rotor into static pressure, due to the pressure recovery within their passages.

\section{Heat Transfer Data}

\section{Surface contours}

Fig.7 indicates surface contours of the heat transfer coefficient on the target plate normalized with the maximum value appeared on these data, approximately 300 $\mathrm{W} / \mathrm{m}^{2} \mathrm{~K}$ on the stage configuration at $Z / D=0.2$ and maximum rotational speed. For both cases heat transfer is
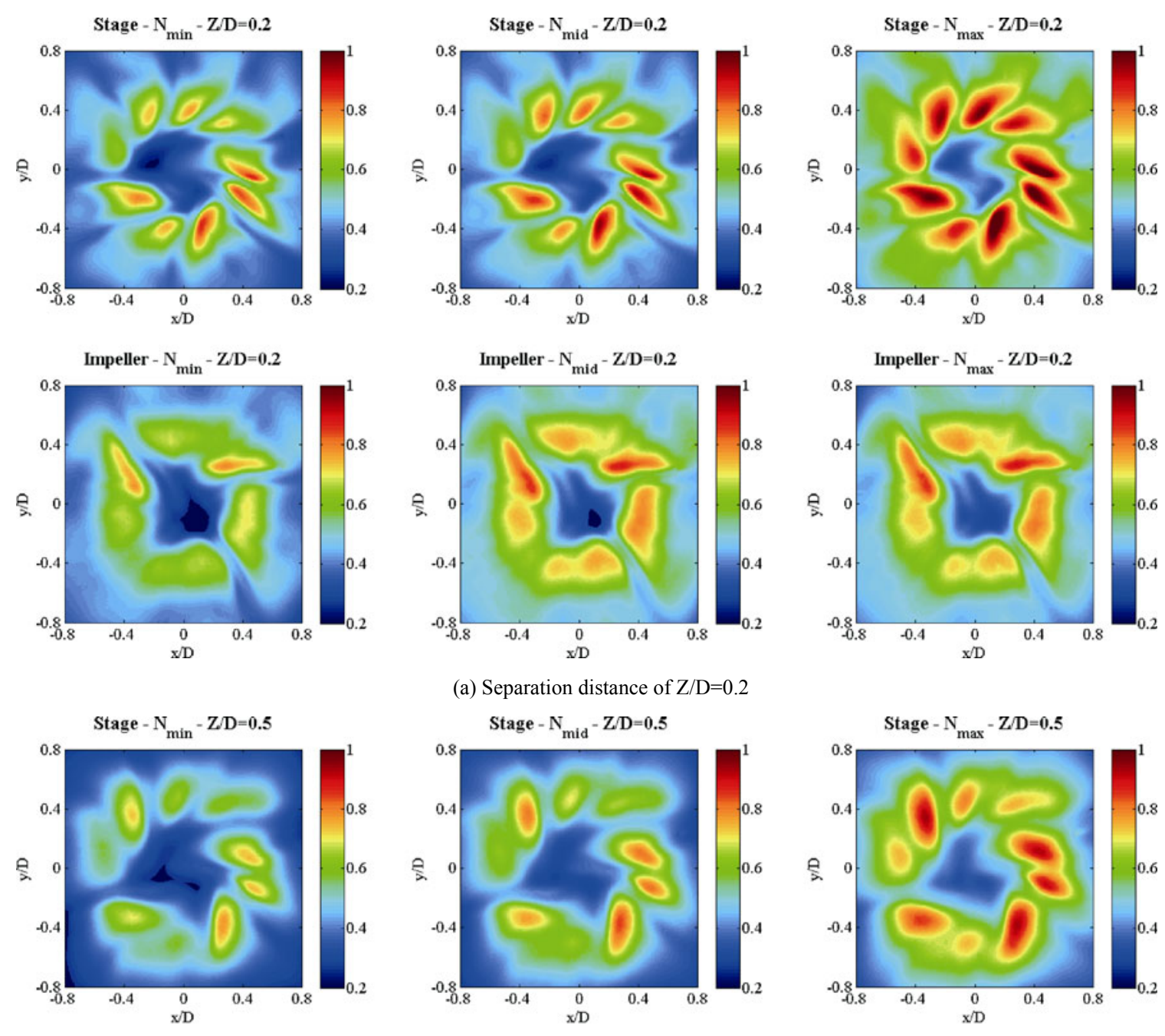

(a) Separation distance of $\mathrm{Z} / \mathrm{D}=0.2$
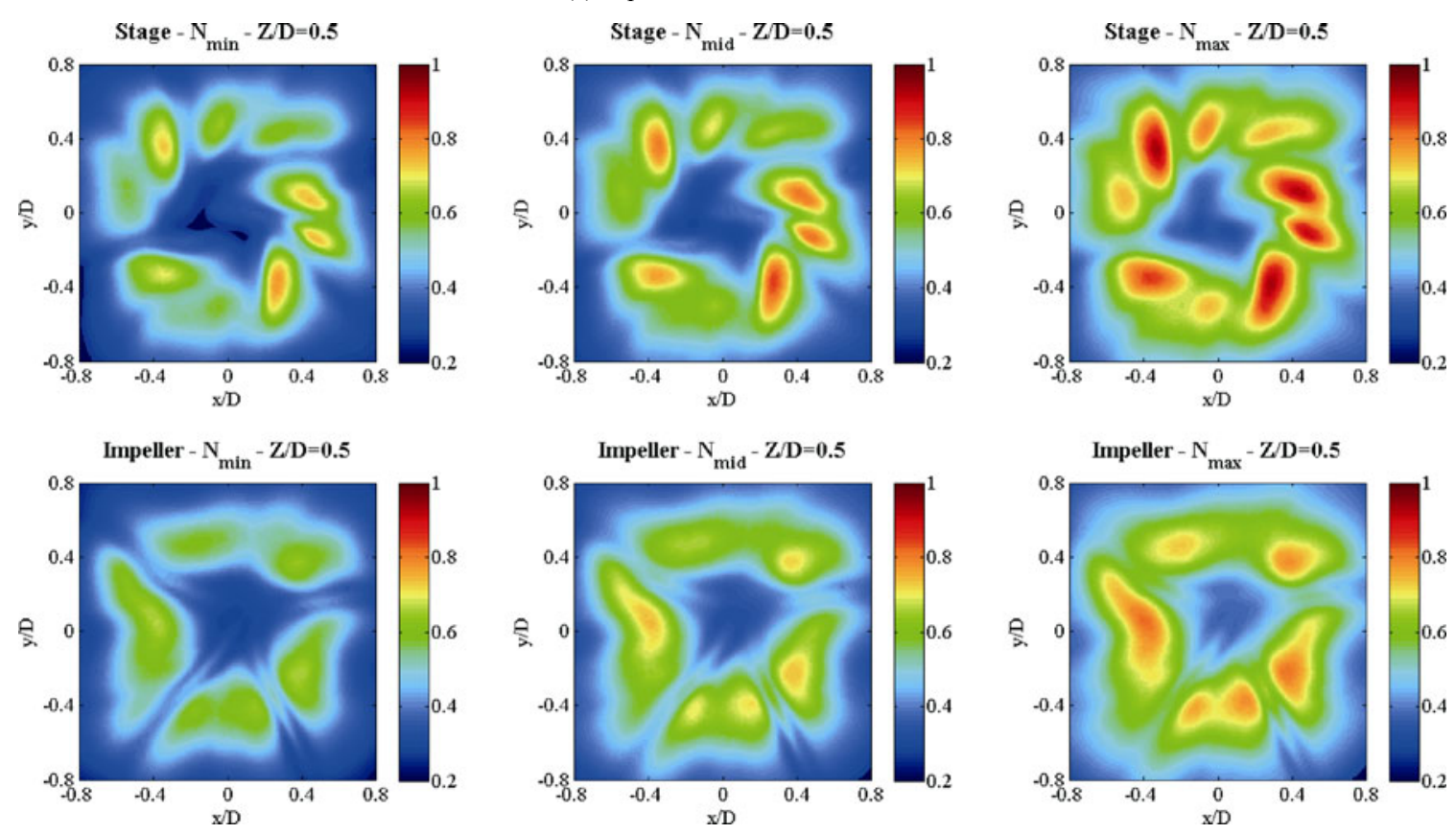

(b) Separation distance of $\mathrm{Z} / \mathrm{D}=0.5$

Fig. 7 Normalized contours of surface heat transfer coefficient on the target plate for the fan impeller and the fan stage configuration 
enhanced with increasing rotational speed in agreement with the basics of the heat transfer theory. However, heat transfer distribution is highly affected by the exit flow angles from the fan blades and the diversion of the flow around the motor supports at the fan outlet. In the case of a complete fan stage and $Z / D=0.2$, stators restore the air flow in axial direction and normal to the target plate. As a result, peak values of heat transfer rate appear as traces of the guide vanes due to the increased velocities at the wake of the stator blades. On the other hand, the distribution of the heat transfer coefficient of a single fan impeller is more uniform and the discontinuations appeared are due to the supports of the fan motor similar to [20]. All the surface contours indicate a central region (dark blue color) where the low values of heat transfer coefficient is a direct consequence of the fan hub since the net exit area of the flow is actually a ring where $R_{h} / R_{t}=0.4$.

Similar results are observed at $Z / D=0.5$, however, the overall heat transfer coefficient is considerably lower indicating a degradation of heat transfer rate as the separation distance increases. Additionally, the ring of the high heat transfer rate (green and red color) appears closer to the edges of the target plate indicating a spreading of the flow at higher $Z / D$. Note also that the heat transfer in the central "uncooled" area (fan hub) is enhanced in the case of a single fan impeller. This is probably, due to the absence of stator blades where the remaining swirl of the flow induced by the rotor forces the jet ring produced by the fan to move in the radial direction and hence in the fan hub region.

\section{Local heat transfer rate}

Fig. 8 indicates the local heat transfer distribution in terms of Nusselt number, in the angular direction $(R / D=0.1$ and 0.35$)$ at $6000 \mathrm{r} / \mathrm{min}$ and the three separation distances. At $Z / D=0.2$ and $R / D=0.35$ the peaks of the heat transfer coefficient at the wake of the stator blades are clearly seen as stator blade wake traces while the distribution of the heat transfer in the case of the fan impeller is slightly more uniform providing smaller fluctuations. Closer to the center of the impingement region $(R / D=0.1)$ the $\mathrm{Nu}$ number distribution for the two cases lies at the same level is more uniform due to the smaller impact of the wake of the blades. At $Z / D=0.5$, similar results are obtained, however, close to the stagnation region $(R / D=0.1)$ the achievable heat transfer rate is slightly higher in the case of a single fan impeller. The difference between the two cases is more evident at $Z / D=1$ where the heat transfer range of the fan impeller is considerably higher than the case of the fan stage not only in the stagnation region but also at a greater radial distance $(R / D=0.35)$. Similar trends observed by a few studies focused swirling impinging jets [21-23]. They reported enhanced heat transfer rates in the stagnation region at low swirl numbers and $Z / D$ between 1 and 2 . Swirl velocity enhances the spreading of the jet and the mixing with the surroundings resulting in higher turbulence values and thus higher heat transfer coefficient. However, at very low $Z / D(0.2-0.5)$ there is no space for the development of the jet potential core and as a consequence the heat transfer rate is mainly affected by the amount of mass-flow which is the same in the case of the fan impeller and the fan stage configuration.
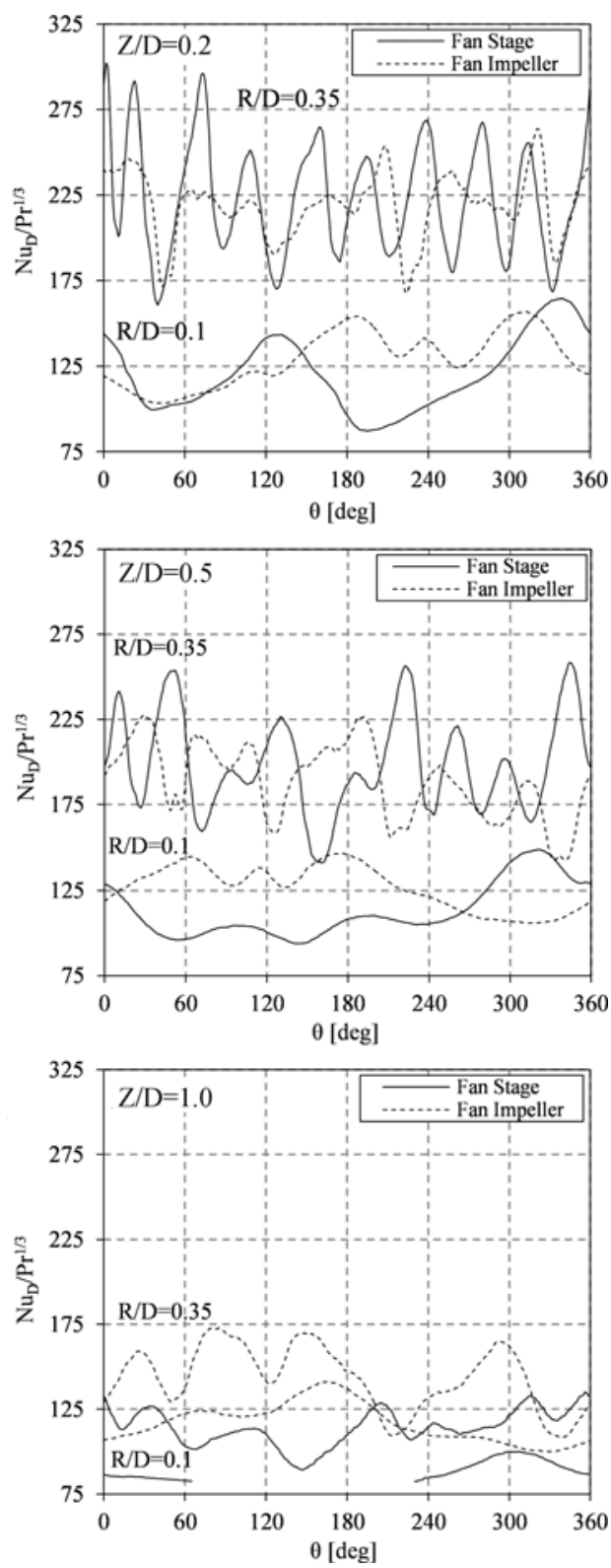

Fig. 8 Angular $\mathrm{Nu}$ number distribution at $6000 \mathrm{r} / \mathrm{min}$ and $\mathrm{Z} / \mathrm{D}=0.2,0.5$ and 1 .

\section{Average heat transfer rate}

The area averaged $\mathrm{Nu}$ number ratio on the target plate is indicated in Fig. 9 as a function of the separation distance $(Z / D)$ and the rotational speed $(N)$. In the first part 
of the figure is observed a decrease of the average heat transfer rate as the separation distance increases from 0.2 to 1 fan diameters. Note that the average heat transfer rate achieved by the fan impeller and fan stage is fairly the same over the entire range of speed lines at low separation distances $(Z / D=0.2$ and 0.5$)$ since there is no space for the development of the jet and the heat transfer rate is mainly affected by the amount of mass-flow, which is the same for the two cases. In particular, at $Z / D=0.2$ and $Z / D=0.5$ the maximum difference between the $N u$ number ratio of the fan impeller and the fan stage configuration is $2.6 \%$ and $1.3 \%$, respectively as shown in Table 1 . However, further increase of separation distance $(Z / D=1)$ allows a small development of the fan jet and therefore the average heat transfer is also affected by the flow conditions at the fan outlet. Absence of stators, in the case of a fan impeller, result in swirling flow conditions and enhanced cooling capabilities for the entire range of rotational speeds. The average heat transfer rate achieved by the fan impeller at $Z / D=1$ is approximately $25 \%$ higher compared to the complete fan stage; percentage which is fairly enough in order to have a positive impact on the operation of an electronic device. Similar results on the averaged heat transfer obtained by [23].

\section{Experimental Uncertainties}

An uncertainty analysis performed on the heat transfer experimental results of this study in order to provide in-
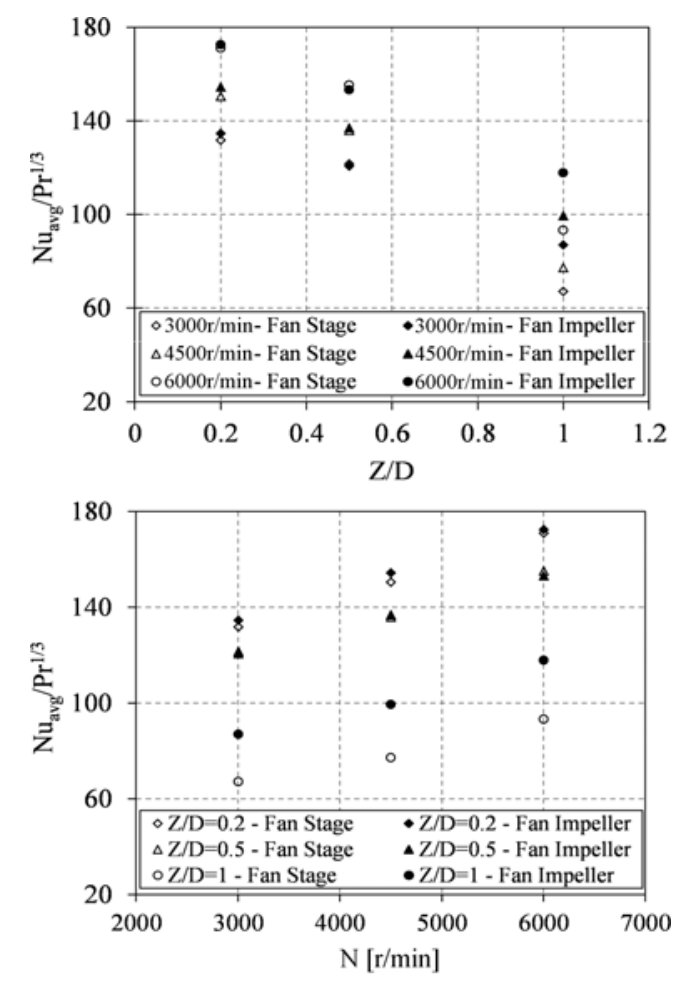

Fig. 9 Area averaged $\mathrm{Nu}$ number ratio as a function of $\mathrm{Z} / \mathrm{D}$ and rotational speed (rpm)
Table 1 Area averaged Nu number ratio on the target plate

\begin{tabular}{lccc}
\hline & $\mathrm{Nu}_{\text {avg }} / \mathrm{Pr}^{1 / 3}$ & & \\
\hline $\mathrm{N}[\mathrm{r} / \mathrm{min}]$ & & 3000 & \\
$\mathrm{Z} / \mathrm{D}$ & 0.2 & 0.5 & 1 \\
Fan Stage & 131.75 & 121.59 & 67.13 \\
Fan Impeller & 134.6 & 120.67 & 86.95 \\
Difference (\%) & 2.14 & 0.76 & 25.73 \\
$\mathrm{~N}$ [r/min] & & 4500 & \\
$\mathrm{Z} / \mathrm{D}$ & 0.2 & 0.5 & 1 \\
Fan Stage & 150.5 & 135.92 & 77.23 \\
Fan Impeller & 154.46 & 136.9 & 99.4 \\
Difference (\%) & 2.60 & 0.72 & 25.10 \\
$\mathrm{~N}$ [r/min] & & 6000 & \\
Z/D & 0.2 & 0.5 & 1 \\
Fan Stage & 171 & 155.27 & 93.28 \\
Fan Impeller & 172.5 & 153.26 & 117.84 \\
Difference (\%) & 0.87 & 1.30 & 23.27 \\
\hline
\end{tabular}

formation for the effect of measurement errors and their propagation on the calculation of the heat transfer coefficient. The estimation of the uncertainties associated within the current investigation is based on the method of small perturbations [24], which has been successfully applied in heat transfer measurements obtained with a transient liquid crystal technique [25-26].

The effect of each type of measurement error on the area averaged heat transfer rate is considered in isolation. The error analysis was performed by applying small perturbations in the test case of a fan stage at $Z / D=0.2$ and $N=4500 \mathrm{r} / \mathrm{min}$. The results are shown in Table 2 where the maximum error in the calculation of heat transfer coefficient is approximately $11 \%$.

Table 2 Uncertainty analysis of the experimental results

\begin{tabular}{ccccc}
\hline & & Values & Error & Error in $\mathrm{h}_{\text {avg }}[\%]$ \\
\hline $\mathrm{T}_{\mathrm{j}}$ & {$\left[{ }^{\circ} \mathrm{C}\right]$} & 43 & \pm 0.25 & 1.89 \\
$\mathrm{~T}_{\mathrm{i}}$ & {$\left[{ }^{\circ} \mathrm{C}\right]$} & 20 & \pm 0.15 & 1.13 \\
$\mathrm{~T}_{\mathrm{TLC}}$ & {$\left[{ }^{\circ} \mathrm{C}\right]$} & 31.5 & \pm 0.3 & 2.63 \\
$\mathrm{a}\left(\mathrm{\times 10} 0^{-7}\right)$ & {$\left[\mathrm{m}^{2} / \mathrm{s}\right]$} & 1.08 & \pm 0.022 & 3.58 \\
$\mathrm{t}$ & {$[\mathrm{s}]$} & 10 & \pm 0.05 & 1.85 \\
& \multicolumn{2}{c}{ Maximum error in $\mathrm{h}_{\text {avg }}$} & & 11.1 \\
\hline
\end{tabular}

\section{Summary and Conclusions}

In the present work, the effect of stators on the performance curves and the heat transfer capabilities of a small axial fan impeller, followed by nine stator blades of the same hub to tip ratio in the case of a complete fan stage, were experimentally investigated. The constant 
speed stage performance method and the transient liquid crystal technique were used for the performance and the heat transfer experiments, respectively. An error propagation analysis indicated that the maximum error in the calculation of the area averaged heat transfer coefficient is approximately $11.1 \%$ which is a fairly good value for a transient heat transfer experiment.

The results indicated that fan efficiency and heat transfer distributions are affected by the flow conditions at the fan outlet. The findings of this investigation can be summarized as follows:

Stator installation results in higher efficiency (in the order of $10 \%$ ) and hence more economical operation at a given massflow rate and rotational speed.

The operation range, the specific fan power and the velocity triangles at the rotor blades are not affected by any stator installation and remain the same for the two studied cases.

In general, the heat transfer removal capabilities of a small axial fan impeller/stage are increased by reducing the separation distance $(Z / D)$ between the fan and the cooling object and increasing the rotational speed.

At low separation distances $(Z / D=0.2-0.5)$ the local heat transfer distribution is highly affected by the conditions at the fan outlet. Peak values of heat transfer appear as traces of the stator blades in the case of a complete stage while the distribution is more uniform when only a fan impeller is used.

At low $Z / D$ no detrimental differences were found in the area averaged heat transfer coefficient between the two studied cases. However, at $Z / D=1$, increased heat transfer rate of approximately $25 \%$ is observed in the case of a fan impeller which is assumed enough to affect the operability of an electronic device.

\section{Acknowledgements}

The authors acknowledge Georgios Michailidis from École Polytechnique (Paris, France) for his contribution during the post processing of experimental data as well as Prof. Jens von Wolfersdorf and Prof. Bernhard Weigand from ITLR of Stuttgart University (Germany) for their overall support during the design of the heat transfer test rig.

\section{References}

[1] Mohamend, M. M. (2006). Air Cooling Characteristics of a Uniform Square Modules Array for Electronic Device Heat Sink,. Applied Thermal Engineering, 26, 486-493.

[2] Chomdee, S., \& Kiatsiriroat, T. (2006). Enhancement of Air Cooling in Staggered Array of Electronic Modules by Integrating Delta Winglet Vortex Generators. Interna- tional Communications in Heat and Mass Transfer, 618-626.

[3] Jiang, J. Z., \& Lin, S. (2001). Similarity of Heat Transfer on Heat Source Elements in the Entrance Region in Electronic Equipment. Journal of Thermal Science, 10(2), 164-169.

[4] Roy, G., Palm, S., \& Nguyen, C. (2005). Heat Transfer and Fluid Flow of Nanofluids in Laminar Radial Flow Cooling. Journal of Thermal Science, 14(4), 362-367.

[5] Icoz, T., \& Jaluria, Y. (2004). Design of Cooling Systems for Electronic Equipment Using Both Experimental and Numerica Inputs. Journal of Electronic Packaging, 126, 465-471.

[6] Sathe, S., \& Samakia, B. (1998). A Review of Recent Developments in Some Practical Aspects of Air-Cooled Electronic Packages. Journal of Heat Transfer, 120, 830-839.

[7] Garimella, S. V. (2006). Advances in Micro-Scale Thermal Management Technologies for Microelectronics. Microelectronics Journal, 37, 1165-1185.

[8] Holloworth, R., \& Durbin, S. (1992). Impingement Cooling of Electronics. Journal of Heat Transfer, 114, 607-613.

[9] Brizzi, E., Bernhard, A., Bousgarbies, J., Dorignac, E., \& Vullierme, J. (2000). Study of Several Impinging Jets. Journal of Thermal Science, 9(3), 217-223.

[10] Quan, D., Liu, S., Li, J., \& Liu, G. (2005). Cooling Performance of an Impingement Cooling Device Combined with Pins. Journal of Thermal Science, 14(1), 56-61.

[11] Weigand, B., \& Spring, S. (2009). Multiple Jet Impingements - A Review. Int. Symp. on Heat Transfer in Gas Turbine Systems. Antalya, Turkey.

[12] Wang, L., Jin, Y., Cui, B., Jin, Y., Lin, J., Wang, Y., et al. (2010). Factors Affecting Small Axial Cooling Fan Performance. Journal of Thermal Science, 19(2), 126-131.

[13] Shiomi, N., Jin, Y., Kaneko, K., Kinoue, Y., \& Setoguchi, T. (2008). Flow Fields with Tip Leakage Vortex in a Small Axial Cooling Fan. Journal of Thermal Science, 17(2), 156-162.

[14] Shigemitsu, T., Fukutomi, J., \& Okabe, Y. (2010). Performance and Flow Condition of Small-Sized Axial Fan and Adoption of Contra-rotating Rotors. Journal of Thermal Science, 19(1), 1-6.

[15] Hidaka, R., Kanemoto, T., \& Sunada, T. (2008). Performance and Accoustic Noise of Micro Multi-blade Fan. Journal of Thermal Science, 17(4), 343-348.

[16] Baughn, J. W. (1995). Liquid Crystal Methods for Studying Turbulent Heat Transfer. International Journal of Heat and Fluid Flow, 16, 365-375.

[17] Ireland, P. T., \& Jones, T. V. (2000). Liquid Crystals Measurements of Heat Transfer and Surface Shear Stress. 
Measurement Science and Technology, 11, 969-986.

[18] Stasiek, J. A., \& Kowalewski, T. A. (2002). Thermochromic Liquid Crystals Applied for Heat Transfer Research. Opto-Electronics Review, 10(1), 1-10.

[19] Gillespie, D., Ireland, P., \& Wang, Z. (1996). Heating Element. British Patent Application, PCT/GB96/02017.

[20] Stafford, J., Walsh, E., \& Egan, V. (2009). Characterizing Convective Heat Transfer Using Infrared Thermography and the Heated-Thin-Foil Technique. Measurement Science and Technology, http://iopscience.iop.org./09570233/20/10/105401(11pp)

[21] Ichimiya, K., \& Tsukamoto, K. (2010). Heat Transfer Characteristics of a Swirling Laminar Impinging Jet. Journal of Heat Transfer, 132, 012201/1-5.

[22] Uddin, N., Neumann, S. O., Lammers, P., \& Weigand, B. (2008). Thermal and Flow Field Analysis of Turbulent Swirling Jet Impingement Using LES. High Performance
Computing in Science and Engineering, Springer, Heidelberg, Part 5, 301-315.

[23] Lee, D. H., Won, S., Kim, Y., \& Chung, Y. (2002). Turbulent Heat Transfer from a Flat Surface to a Swirling Round Impinging Jet. International Journal of Heat and Mass Transfer, 45, 223-227

[24] Moffat, R. J. (1988). Describing the Uncertainties in Experimental Results. Experimental Thermal and Fluid Science, 1, 3-17.

[25] Chambers, A. C., Gillespie, D., Ireland, P. T., \& Dailey, G. M. (2005). The Effect of Initial Cross Flow on the Cooling Performance of a Narrow Impingement Channel. Journal of Heat Transfer, 127, 358-365.

[26] Terzis A., Wagner, G and Ott P. (2012) Hole Staggering Effect on the Cooling Performance of Narrow Impingement Passages, ASME Turbo Expo 2012/GT68323, Glasgow, Scotland. 